3 Moyses HE, Johnson MJ, Leaf $\mathrm{AA}$, et al. Early parenteral nutrition and growth outcomes in preterm infants: a systematic review and meta-analysis. Am J Clin Nutr 2013;97:816-26.

\section{SP 03 HOW SUCCESSFUL ARE WE AT DELIVERING NUTRITION?}

Zoe Lansdowne. Tamanna Moore Sheffield Teaching Hospitals NHS Foundation Trust

\subsection{6/archdischild-2015-308634.3}

Aims Current evidence shows that administering intravenous amino acids as soon as possible after birth is beneficial to extremely low birthweight (ELBW) infants in terms of reversing protein loss and promoting growth ${ }^{12} 3$ although there are many barriers to achieving this. The aim of this audit was to establish how successful our level 3 neonatal unit is at delivering nutrition to these infants, over the first 14 days of life and whether we achieve our growth rate target of $10-15 \mathrm{~g} / \mathrm{kg} /$ day.

Methods The details of all infants born $<28$ weeks or $<1 \mathrm{~kg}$ from 1st January to 31st March 2014 were analysed retrospectively. Data was collected from the patients' medical notes, including parenteral nutrition (PN) prescriptions, fluid prescriptions and observation charts.

Results Over the 3 month period, 21 patients met the inclusion criteria, although one patient was then excluded as they were not admitted until 36 hours after birth. From these 20 patients, it was found that the average time from birth to first receiving any PN was 15 hours 8 mins, ranging from 4 hours 12 mins to 45 hours 40 mins. On average patients received $0.66 \mathrm{~g} / \mathrm{kg} /$ day of protein in the first 24 hours of life.

Three patients were excluded from further data analysis (one died and two were discharged before day 14). The remaining 17 patients received an average of $2.15 \mathrm{~g} / \mathrm{kg} /$ day of protein (enteral and parenteral) each day over the first 14 days of life. The maximum amount of protein received in 24 hours by an individual patient was $3.46 \mathrm{~g} / \mathrm{kg} /$ day. Average weight gain was $2.97 \mathrm{~g} / \mathrm{kg} /$ day, with a maximum weight gain of $13.82 \mathrm{~g} / \mathrm{kg} / \mathrm{day}$. The greatest weight loss was $7.56 \mathrm{~g} / \mathrm{kg} / \mathrm{day}$.

Weight gain was found to be inversely related to the number of hours until PN was first started $\left(\mathrm{R}^{2}=0.59\right)$ and it took on average 6 hours and 24 mins for $\mathrm{PN}$ to be started once central access had been confirmed suitable for PN use (range 5 mins to 25 hrs 30 mins). There was a slightly positive correlation between weight gain and protein intake on day 1 $(\mathrm{R} 2=0.31)$.

On reviewing all 20 infants, it was found that on average 13\% of the PN quantities prescribed were never administered.

Conclusion ELBW infants need intravenous amino acids soon after birth to reverse protein loss and promote growth. It has been shown that a delay in the time from birth to starting $\mathrm{PN}$ has detrimental effects on weight gain over the first 14 days of life.

From this audit it can be concluded that it is imperative that new ways are found to reduce the amount of time it takes before $\mathrm{PN}$ is started after birth and that the amount of protein administered is increased.

\section{REFERENCES}

1 Ehrenkranz RA. Early, aggressive nutritional management for very low birth weight infants: what is the evidence? Semin Perinatol 2007;31:48-55.

2 Stephens BE, Walden RV, Gargus RA, et al. First-week protein and energy intakes are associated with 18-month developmental outcomes in extremely low birth weight infants. Pediatrics 2009;123:1337-43. 